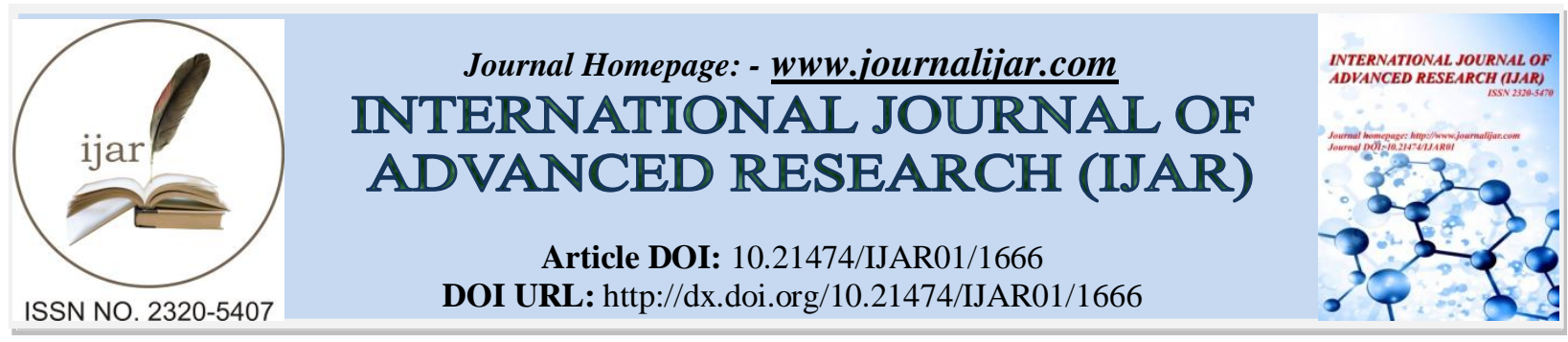

RESEARCH ARTICLE

\title{
AZYGOS VEINS VARIATIONS IN VIEW OF THEIR DEVELOPMENTAL BASIS: CASE REPORT.
}

Samy Ismail Ahmed ${ }^{1^{*}}$ and Tahir Osman $\mathrm{Ali}^{2}$.

1. Department of Anatomy, Faculty of Medicine, Najran University, Saudi Arabia.

2. Faculty of Graduate Studies \& Scientific Research, National Ribat University, Sudan.

\section{Manuscript Info}

Manuscript History

Received: 12 July 2016

Final Accepted: 13 August 2016

Published: September 2016

Key words:-

azygos system; clinical; vena caval; mediastinum; cadavers; connections

\section{Abstract}

Introduction:- The azygos system of veins anatomical variations are usually explained on the basis of their embryological development. These variations are deserves to be highlighted and reported. Because, for its clinical importance as it acts as a collateral circulation and an alternative pathway in the case of vena caval obstructions, and it is essential for radiographic imaging and avoiding posterior mediastinum surgical complications for optimal patient 's outcome.

Material and method:- A dissection of posterior mediastinum of the adult two male cadavers in our anatomy department, showed multiple abnormalities of the azygos venous system

Result:- In case (1), the azygos vein, formed by the right subcostal vein only, with an absence of the right ascending lumbar vein. The hemiazygos vein was found to be formed by the union between the left subcostal and the left eleventh posterior intercostal veins. While, The $6^{\text {th }}$ and $7^{\text {th }}$ left posterior intercostal veins conjugated and formed a single root which in turn received the accessory hemiazygos vein that appear to be formed by the $3^{\text {rd }}, 4^{\text {th }}$ and $5^{\text {th }}$ left posterior intercostal veins. In case (2), the left azygos venous line was ill defined and the lower eight left posterior intercostal veins were opening independently into the azygos vein by three venous connections. We discussed these variations in view of their embryological developmental basis.

Conclusion:- Obstruction of the cardinal veins normal developmental manner can result in azygos veins abnormalities.

Copy Right, IJAR, 2016,. All rights reserved.

\section{Introduction:-}

The complex embryologic development of the azygos system of veins makes it susceptible to wide variations that may affect its normal origin, course, termination as well as its normal drainage ${ }^{[1]}$.

These variations may misdiagnose as vascular diseases or other abnormalities. Therefore, knowledge of such anomalies and their embryological basis are very important specially during the posterior mediastinal computed tomography and magnetic resonance imaging reports, and surgery of large vessels to avoid their injuries and unnecessary bleeding [2], [3], [4]. 
The azygos vein drains the posterior walls of the thorax and abdomen by many tributaries, including the eight lower right intercostal veins, the right superior intercostal vein, the superior and inferior hemiazygos veins, and numerous mediastinal veins ${ }^{[5]}$. It is usually formed by the union of the right ascending lumbar vein and the right subcostal vein anterior to the twelfth thoracic vertebral body. It passes through the aortic opening of the diaphragm and ascends in the posterior mediastinum on the right side of the thoracic aorta to the level of the fifth thoracic vertebra. Here it arches forward above the root of the right lung to empty into the posterior surface of the superior vena cava ${ }^{[6]}$. The hemiazygos vein is usually formed by the union of the left ascending lumbar vein and the left subcostal vein, receive the lower left three posterior intercostal veins and join the azygos at the level of $8^{\text {th }}$ thoracic vertebra. While the accessory hemiazygos receive the $5^{\text {th }}, 6^{\text {th }}, 7^{\text {th }}$ and $8^{\text {th }}$ left posterior intercostal veins and empty into the azygos at the level of $7^{\text {th }}$ thoracic vertebra. Subsequently, the azygos veins acts as a collateral circulation and an alternative pathway in case of caval vein occlusion, portal hypertension and liver cirrhosis ${ }^{[7,8]}$.

\section{Material and Method:-}

A dissection of posterior mediastinum of the adult two male cadavers in our anatomy department, showed multiple abnormalities of the azygos venous system. The results are illustrated in Figures (1,2 \& 3).

\section{Case (1):-}

The azygos vein was appearing to be formed by the right subcostal vein only, without any contribution from the right renal vein, inferior vena cava or ascending lumbar veins (Figure 1).it receive the hemiazygos at the level of $8^{\text {th }}$ thoracic vertebra and the accessory hemiazygos at level of $6^{\text {th }}$ thoracic vertebra. After it receives the hemiazygos vein, the azygos vein lies in the midline.

The hemiazygos vein was found to be formed by the union between the left subcostal and the left eleventh posterior intercostal veins (Figure 2). The hemiazygos vein appeared pendulous and receives the $10^{\text {th }}, 9^{\text {th }}$ and $8^{\text {th }}$ left posterior intercostal veins (Figure 2). The $6^{\text {th }}$ and $7^{\text {th }}$ left posterior intercostal veins conjugated and formed a single root which in turn received the accessory hemiazygos vein that appear to be formed by the $3^{\text {rd }}, 4^{\text {th }}$ and $5^{\text {th }}$ left posterior intercostal veins.

\section{Case (2):-}

This case showed complete absence of the hemiazygos veins, and the lower eight posterior intercostal veins drained bilaterally to the azygos vein (Figure 3). The left $12^{\text {th }}$ and $11^{\text {th }}$ posterior intercostals vein united together and joined the azygos vein at the level of $11^{\text {th }}$ thoracic vertebra. Left $10^{\text {th }}, 9^{\text {th }}$ and $8^{\text {th }}$ posterior intercostals veins conjugated and opened to the azygos vein at the level of $8^{\text {th }}$ thoracic vertebra after forming one single root (Figure 3 ). While the $5^{\text {th }}$ and $6^{\text {th }}$ joined the $7^{\text {th }}$ left posterior intercostal vein which drained into the azygos vein at the level of $7^{\text {th }}$ thoracic vertebra (Figure 3).

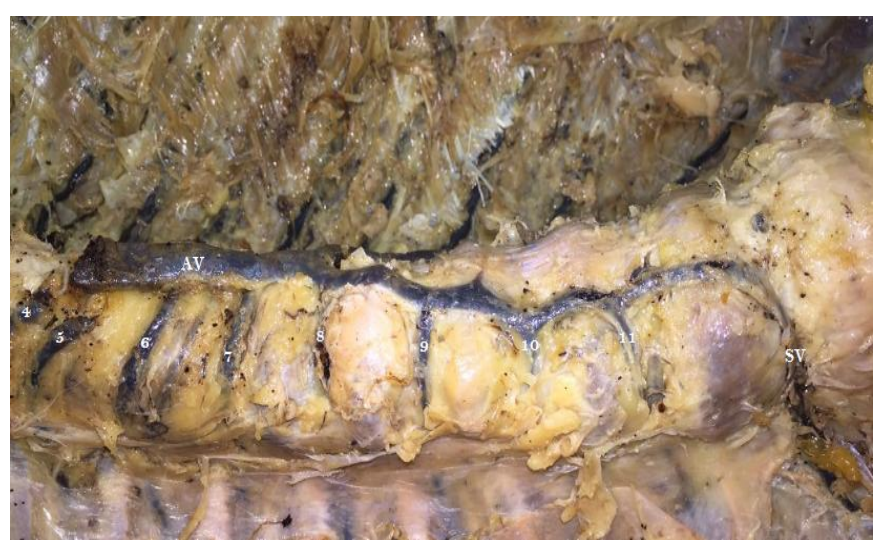

Figure 1:- Showed: Azygos vein; AV, Rt subcostal vein; SV, (4 - 11), Rt posterior intercostal veins. 


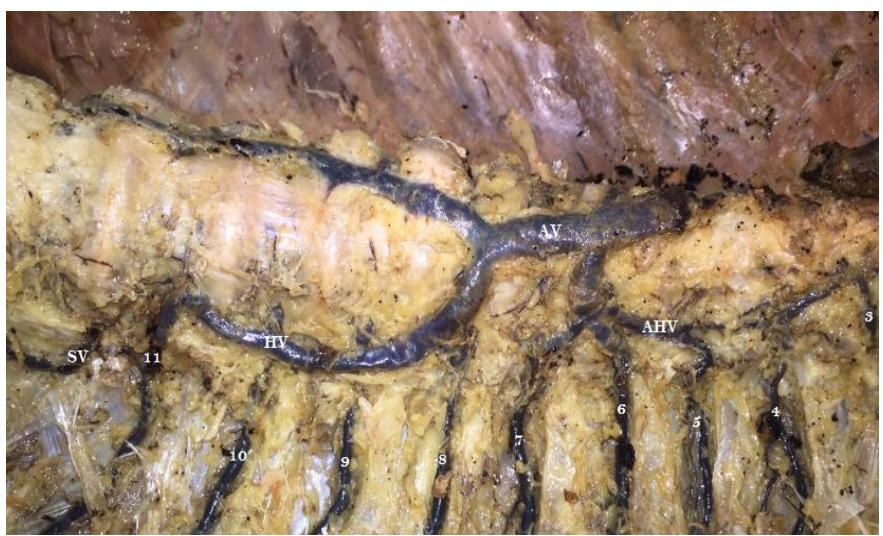

Figure 2:- Showed: Azygos vein; AV, Lt subcostal vein; SV, Hemiazygos vein; HV, Accessory hemiazygos vein; AHV, (3-11); Lt. posterior intercostal veins.

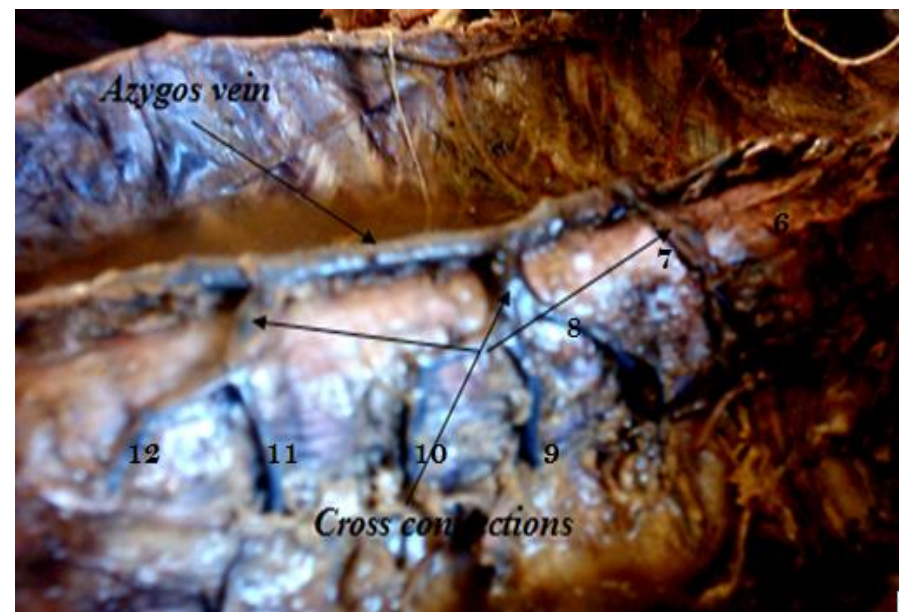

Figure 3:- Showed: Azygos vein, (6 - 11) Lt posterior intercostal veins and (12) subcostal vein.

\section{Discussion:-}

Azygos venous system formation depends primarily on various modifications during the development of the cardinal venous complex that constitutes the main venous drainage system of the embryo which appears in the third week of intrauterine life ${ }^{[9]}$. The complicated development of these veins accounts for the fact that deviations from the normal pattern are common.

Although the azygos system developmental origin is somewhat controversial, the azygos vein is often formed by the right supracardinal vein and the terminal part of the right posterior cardinal vein (right azygos line). Whereas, the hemiazygos and accessory hemiazygos veins are formed by supracardinal vein the terminal part of the left posterior cardinal vein (left azygos line). The transverse anastomosis between the azygos and hemiazygos veins is formed by the persistence of the embryological subcentral anastomosis between right and left supracardinal veins $[\mathbf{1 0 , 1 1 ]}$

In our case (1), formation of the azygos vein by the right subcostal vein only was also reported by Alves, E. C et al [7] and the formation of the hemiazygos vein by the union of the left subcostal and $11^{\text {th }}$ posterior intercostal veins was seldom reported ${ }^{[4]}$. Such varieties might be due to the undeveloped or atrophied abdominal part of the right supracardinal vein which forms the right ascending lumbar vein with the absence of the left supra - subcardinal anastomosis which forms the lumbar azygos vein ${ }^{[12-14]}$.

The accessory hemiazygos vein normally receives the $5^{\text {th }}-8^{\text {th }}$ intercostal veins but, in the present case (1), this vein received the 3 th $-5^{\text {th }}$ left and joined the common trunk that formed by $6^{\text {th }}$ and $7^{\text {th }}$ posterior intercostal veins. This drainage pattern was reported by Srijit Das and Shipra Paul ${ }^{[15]}$.This explained by unusual appearance and disappearance of some parts of the left supracardinal vein. 
In our case (2), the absence of the hemiazygos veins with independent left lower eight posterior intercostal veins drained into the azygos vein through three venous connections was supported by Pyrozwiski J, et al ${ }^{[16]}$ and Quraishi $\mathrm{MB}$, et al ${ }^{[17]}$.This thought to be formed by undeveloped left supracardinal vein with persistent of three extraordinary intersegment anastomosis.

\section{Conclusion:-}

Obstruction of the cardinal veins normal developmental manner can result in azygos veins abnormalities. Knowledge of azygos system of veins variations is of utmost important to identify, especially for radiologist who may misdiagnosed these anomalies as an aneurysm, tumor or enlarged lymph node in computed tomography and magnetic resonance imaging scans.

Hemorrhage is the most troublesome intra-operative hazard which can be caused by accidental injury to such developmental anomalies. Therefore, pre - operative awareness to such anomalies are of great value for surgeons.

\section{References:-}

1. P. L. Williams, L. H. Bannister, and M.M. 1995. Berry. Gray's Anatomy, 38th British edition, Churchill Livingstone, New York, NY, USA.

2. Y. Srinivasa Rao, b Arindom Banerjee. 2014. Anatomical variations of the azygos venous system. Int J Biol Med Res. vol. 5, no. 4, pp. 4535-4538.

3. J. Pyrzowski, J.H. Spodnik, A. Lewicka, A. Popławska, S. Wojcik. 2007. A case of multiple abnormalities of the azygos venous system: a preaortic interazygos vein. Folia Morphol, Vol. 66, No. 4, pp. 353-355.

4. Narayanan.G. , Aruna. S , Balaji T.K., Kannan.G., Venkateshgobi.V. 2013. A Study on Azygos System of Veins and Venous Aneurysm. Journal of Nursing and Health Science (IOSR-JNHS), Vol. 2, no 2, pp.1940 2320.

5. Moore, K. \& Dalley, A.S. Anatomia Orientada para a Clinica. 2001. 4a ed. Rio de Janeiro, Guanabara Koogan.

6. Richard S. Snell. 2004. Clinical anatomy. Lippincott Williams and Wilkins; 7th dEdition Philadelphia, Pennsylvania.

7. Alves, E. C.; Porciuncula Junior, R. W.; Monte Bispo, R. F.; De Sousa-Rodrigues, C. F. \& Da Rocha, A. C. 2011. Formation of the azygos vein. Int. J. Morphol. vol. 29, no 1, pp.140-143.

8. Arslan G, Cubuk M, Ozkaynak C, et al. 2000. Absence of the azygos vein. Clin Imaging. 24 (3): 157-158.

9. Standring S. 2005. Gray's Anatomy. The Anatomical Basis of Clinical Practice. 39th ed. Churchill Livingstone. Pp.1025-1027, 1045-1050.

10. Narayanan.G. , Aruna. S , Balaji T.K., Kannan.G., Venkateshgobi.V.2013. A Study on Azygos System of Veins and Venous Aneurysm. Journal of Nursing and Health Science (IOSR-JNHS).Vol. 2, no 2, pp.1940 -2320.

11. Sadler T W. 2006. Development of Cardiovascular system. Langman's Medical Embryology. 10th ed. Philadelphia, Lippincott Williams \& Wilkins. 12:187-188.

12. Samy Ismail Ahmed Mustafa, Tahir Osman Ali, Aamir Ali Ahmed. 2016. Anatomical variation of the azygos vein in human cadavers. International Journal of Innovation and Scientific Research. Jul. Vol. 25 No. 2, pp. 368-372.

13. Necdet Kocabyyyk, Tunc Kutodlu, Soner Albay, Bulent Yalcyn, Hasan Ozan.2006. Azygos vein system abnormality: case report. Gulhane Typ Dergisi. vol. 48, pp.180-182.

14. Suat Keskin. 2013. Angiography of Azygos Continuation of Inferior Vena Cava with Polysplenia. Eur J Gen Med.vol. 10, no.1, pp. 39-41.

15. Srijit Das and Shipra Paul. 2004. Preaortic Interazygos Vein: A Case Report. Braz. J. morphol. Sci. 21(3), 141143.

16. Pyrozwiski J, Spondnik JH, Lewicka A, et al. 2007. A case of multiple abnormalities of the azygos venous system: a praeaortic interazygos vein. Folia Morphol (Warsz). 66(4):353-5.

17. Quraishi MB, Mufti O, Wase A. 2010. Absent left and right superior vena cava and azygos continuation of inferior vena cava: a rare anomaly of systemic venous return. J Invasive Cardiol. 22: E159-61. 